\title{
The concept of mechanism in biology
}

\author{
Daniel J. Nicholson \\ Konrad Lorenz Institute for Evolution and Cognition Research, Adolf Lorenz Gasse, 2, Altenberg A-3422, Austria
}

\section{A R T I C L E I N F O}

\section{Article history:}

Available online 2 July 2011

\section{Keywords:}

Mechanism

Mechanicism

Machine

Causal explanation

Function

Organization

\begin{abstract}
A B S T R A C T
The concept of mechanism in biology has three distinct meanings. It may refer to a philosophical thesis about the nature of life and biology ('mechanicism'), to the internal workings of a machine-like structure ('machine mechanism'), or to the causal explanation of a particular phenomenon ('causal mechanism'). In this paper I trace the conceptual evolution of 'mechanism' in the history of biology, and I examine how the three meanings of this term have come to be featured in the philosophy of biology, situating the new 'mechanismic program' in this context. I argue that the leading advocates of the mechanismic program (i.e., Craver, Darden, Bechtel, etc.) inadvertently conflate the different senses of 'mechanism'. Specifically, they all inappropriately endow causal mechanisms with the ontic status of machine mechanisms, and this invariably results in problematic accounts of the role played by mechanism-talk in scientific practice. I suggest that for effective analyses of the concept of mechanism, causal mechanisms need to be distinguished from machine mechanisms, and the new mechanismic program in the philosophy of biology needs to be demarcated from the traditional concerns of mechanistic biology.
\end{abstract}

(c) 2011 Elsevier Ltd. All rights reserved.

When citing this paper, please use the full journal title Studies in History and Philosophy of Biological and Biomedical Sciences

'Biological Mechanism is committed logically to a great deal more than is commonly supposed.' (Broad, 1925, pp. 91-92)

\section{Introduction}

The concept of mechanism has recently received a great deal of attention in the philosophy of science. The main catalyst for this new interest has been the realization that scientists, especially biologists, often refer to mechanisms in their inquiries into the phenomena they investigate. This has led to the development of a lively philosophical research program over the past decade that has attempted to make sense of scientists' 'mechanism-talk' and elucidate the role it plays in scientific practice. The standard philosophical strategy has been to begin by offering a general characterization of 'mechanism' that captures the way scientists use this word, and then show the ways in which mechanisms are involved in the explanation of phenomena. The mechanism account that has exerted the greatest influence in the development of this new discourse has been formulated by Machamer, Darden, and Craver (2000). Machamer et al. (MDC, hereafter) conceive mechanisms as 'entities and activities organized such that they are productive of regular changes from start or set-up conditions to finish or termination conditions' (MDC, 2000, p. 3). Glennan (2002) and Bechtel (2006) have also developed their own mechanism accounts. Glennan defines a mechanism for a behaviour as 'a complex system that produces that behavior by the interaction of a number of parts, where the interactions between parts can be characterized by direct, invariant, change-relating generalizations' (Glennan, 2002, p. S344), whereas Bechtel characterizes a mechanism as 'a structure performing a function in virtue of its component parts, component operations, and their organization', adding that 'The orchestrated functioning of the mechanism is responsible for one or more phenomena' (Bechtel, 2006, p. 26).

This emerging mechanism movement aims to provide a new framework in which to tackle a number of classic problems in the philosophy of science. Central among them is the nature of explanation, in which a focus on mechanisms is deemed to constitute an effective antidote to the outmoded deductive-nomological conception of explanation inherited from logical empiricism. In addition, recent literature in the philosophy of science includes mechanism-based accounts of causation (Machamer, 2004),

E-mail address: dan.j.nicholson@gmail.com 
reduction (Craver, 2005; Darden, 2005), models (Craver, 2006; Darden, 2007; Glennan, 2005a), and reasoning in discovery (Bechtel, 2009; Darden, 2006). Moreover, it has been suggested that thinking about mechanisms may help resolve the problem of underdetermination (Glennan, 2005a, pp. 458-459), as well as render unnecessary discussions of laws (Glennan, 2002, p. S348; MDC, 2000, pp. 7-8) and theories (MDC, 2000, pp. 16-17). Nevertheless, despite the general applicability of mechanism-based philosophy of science, it is interesting to note that this research program has developed primarily within the philosophy of biology. Indeed, the most prominent defences and extensive elaborations of the mechanism approach have been advanced by philosophers interested in the life sciences, with book-length mechanism accounts now existing for several biological subdisciplines, including cell biology (Bechtel, 2006), molecular biology (Darden, 2006), and neuroscience (Craver, 2007). This partnership between mechanism-based philosophy and biology is no mere happenstance. In fact, I will show that attending to the role the concept of mechanism has played in the development of biological thought opens up a rich new perspective in which to effectively examine and critically evaluate the recent mechanism discourse.

In a nutshell, what a historically informed perspective reveals is that the term 'mechanism' has come to be used in biology in a number of different senses. As the new mechanism discourse proceeds with an almost complete disregard for how the concept of mechanism has been shaped by the history of its usage, current discussions frequently suffer from the inadvertent conflation of the different meanings of the term. Admittedly, philosophers are generally aware that 'mechanism' is a convoluted concept with a long history, as evidenced by MDC's assertion that 'What counts as a mechanism in science has developed over time and presumably will continue to do so' (MDC, 2000, p. 2). However, most of them deem the potential for semantic confusion minimal because they consider the various meanings of the concept to be neatly associated with discrete, non-overlapping historical periods. Craver (2007, p. 3), for instance, remarks: 'But what is a mechanism? History cannot answer this question. The term mechanism has been used in too many different ways, and most of those uses no longer have any application in biology'. This paper will demonstrate, in opposition to this claim, how an awareness of the semantic breadth of the concept of mechanism afforded by an examination of its history can help uncover a number of important tensions within the new mechanism discourse, as well as provide the necessary philosophical resources for resolving them.

I begin by distinguishing and characterizing the three meanings of the concept of mechanism in biology (Section 2). I then explore the way in which the different senses of 'mechanism' have been used in the history of biology (Section 3), and how they have come to be featured in the philosophical literature, situating the new mechanism discourse in this context (Section 4). Following this, I illustrate the various problems that arise in recent discussions from the inadvertent conflation of the different senses of 'mechanism' (Section 5). Finally, I show what amendments need to be made to current accounts of mechanism to effectively capture the way this concept is used by biologists in their research (Section 6).

\section{The three meanings of 'mechanism' in biology}

The term 'mechanism' is used to mean different things in different contexts. In biology, 'mechanism' has three distinct meanings, which can be distinguished and defined as follows:

(a) Mechanicism: The philosophical thesis that conceives living organisms as machines that can be completely explained in terms of the structure and interactions of their component parts. (b) Machine mechanism: The internal workings of a machine-like structure.

(c) Causal mechanism: A step-by-step explanation of the mode of operation of a causal process that gives rise to a phenomenon of interest.

As this taxonomy illustrates, 'mechanism' may refer to (a) a philosophical thesis about the nature of life and biology, (b) the workings of a machine, and (c) a particular mode of explanation. In order to make the ensuing discussion as clear as possible, I will refrain from using the word 'mechanism' in favour of these three terms, employing it only when referring to the word itself and not to any of its meanings. Let us now examine each of the three senses of 'mechanism' in more detail.

Mechanicism (often called mechanistic philosophy or mechanical philosophy) has its roots in the natural philosophy that emerged from the work and ideas of Galileo Galilei, René Descartes, Pierre Gassendi, Robert Boyle, Isaac Newton and others during the Scientific Revolution. This philosophy is usually associated with a naturalistic, atomistic, and deterministic view of nature that tends to lend itself to mathematical characterization. However, biological mechanicism, or mechanistic biology, has a rather more specific meaning (cf. Allen, 2005; Bertalanffy, 1952; Broad, 1925; Dupré, 2007; Haldane, 1929; Lewontin, 2000; Loeb, 1912; Monod, 1977; Rosen, 1991; Woodger, 1929). It can be characterized in terms of the following key tenets:

1. The commitment to an ontological continuity between the living and the nonliving, exemplified by the quintessential mechanistic conception of organisms as machines, analogous and comparable to man-made artefacts

2. The view that biological wholes (i.e., organisms) are directly determined by the activities and interactions of their component parts, and that consequently all properties of organisms can be characterized from the bottom up in increasing levels of complexity

3. The focus on the efficient and material causes of organisms, and the unequivocal repudiation of final causes in biological explanation

4. The commitment to reductionism in the investigation and explanation of living systems

Mechanicism has been one of the most influential schools of biological thought since the late seventeenth century. It has its origins in the physiological writings of Descartes, though the doctrine has had numerous incarnations through the centuries. Some of the most illustrious biologists of the past three hundred and fifty years have developed their ideas within a mechanistic framework. Famous mechanistic biologists include Giovanni Borelli, Stephen Hales, Antoine Lavoisier, François Magendie, Emil du Bois-Reymond, Hermann von Hemholtz, Carl Ludwig, Wilhelm Roux, and Jacques Loeb. In modern times, the astounding successes of molecular biology have served to consolidate mechanicism as one of the central philosophies of life and biology. Most recently, the emerging field of synthetic biology, with its aim to apply engineering principles in order to design and manufacture living cells from scratch, constitutes the newest expression of the mechanistic research program in biology.

The machine mechanism sense of 'mechanism' is the closest to the etymological roots of the word, which can be traced to the Latin machina and the Greek mechane, terms meaning 'machine' or 'mechanical contrivance'. The notion of machine mechanism has traditionally been employed by biologists to describe machine-like systems, or rather, systems conceived in mechanical terms; that is, as stable assemblies of interacting parts arranged in such a way that their combined operation results in predetermined outcomes. 
Since the time of Descartes, mechanistic biologists have conceived organisms in explicit analogy with the paradigmatic machine mechanism of the age, be it a seventeenth-century clock with its finely-tuned parts operating as a functionally-integrated whole, an eighteenth-century steam-engine consuming chemically-bound energy by combustion and performing work whilst releasing heat, or a twentieth-century computer with its inbuilt program capable of processing information about the environment and responding accordingly. Machine mechanisms, biological and technological, can be studied in isolation and are often decomposable into smaller machine mechanisms.

The causal mechanism sense of 'mechanism', in contrast to the first two, only acquired widespread currency in biology in the twentieth century, though it is the usage of the term that has become predominant today. Causal mechanisms are of fundamental importance in scientific practice because they enable the identification of causal relations. To inquire about the causal mechanism of $\mathrm{P}$ (where $\mathrm{P}$ is the phenomenon of interest) is to inquire about the causes that explain how $\mathrm{P}$ is brought about. ${ }^{1}$ Although the majority of philosophers conceive causal mechanisms as real things in the world (akin to machine mechanisms), I will be arguing in this paper that they are actually better understood as heuristic models which target specific causal relations and thereby facilitate the explanation of the particular phenomena scientists investigate.

I am not, of course, the first to propose that the concept of mechanism needs to be terminologically fragmented to reflect its semantic breadth. In fact, the word 'mechanicism' as I have defined it above has had longstanding currency in the German ('mechanizismus'), French ('mécanicisme'), Italian ('meccanicismo'), and Spanish ('mecanicismo') scholarly literature, where it is commonly used to demarcate this sense of 'mechanism' from the machine mechanism and causal mechanism senses, but for some reason the term has not caught on in the English-speaking world. However, Allen (2005) has recently distinguished between the mechanicism sense (which he calls 'philosophical Mechanism') and the causal mechanism sense (which he calls 'explanatory mechanism'), though he does not discern the machine mechanism meaning of 'mechanism'. On the other hand, Ruse (2005) has distinguished between the machine mechanism and causal mechanism senses (designating the former 'mechanism in the specific sense' and the latter 'mechanism in the general sense'), but he fails to acknowledge the mechanicism meaning. So although previous attempts have been made to distinguish the various senses of 'mechanism', these efforts have tended to only discriminate two of the three meanings of the concept. Consequently, a tripartite distinction such as the one I have proposed in this section is needed to recognize the full semantic breadth of the concept of mechanism.

Proponents of the new mechanism movement may object that such convoluted distinctions are not really necessary, as at least in present philosophical discussions the term 'mechanism' is employed consistently. The reality, however, is that it is not uncommon to come across instances in the new mechanism discourse in which the concept is used in different senses, sometimes even in the same passage. For example, consider the following remark by Craver and Darden (2005, p. 234):

From the perspective of biology [...] one might tell a triumphal story of the success of mechanism [i.e., mechanicism] over various forms of vitalism, as well as over biological theories appealing to intelligent design. Indeed, one cannot open a journal in any field of contemporary biology without encountering appeals to the mechanism [i.e., causal mechanism] for this or that phenomenon. ${ }^{2}$

One final terminological distinction is in order before moving on. It has become customary, following Skipper and Millstein's (2005) analysis, to refer to the recent mechanism discourse as 'the new mechanistic philosophy'. This is a very unfortunate and rather misleading designation, as it suggests that the new philosophical interest in the concept of mechanism represents some sort of continuation of mechanistic philosophy (i.e., mechanicism), which is not in fact the case. Mechanistic philosophy, both as a general doctrine and specifically as it applies to biology, is concerned with the characterization of machine mechanisms. The new mechanism discourse, in contrast, is devoted to examining the role played by causal mechanisms in scientific practice. The new mechanism discourse is not committed to a mechanistic worldview, nor does it prescribe a mechanistic approach in biology. In fact, there is nothing distinctively mechanistic about the new mechanism discourse, other than its focus on 'mechanisms'; and even this is not something it really shares with mechanicism given that each research program understands this concept in a different sense (see Fig. 1). Still, many contemporary philosophers of science routinely refer to explanations appealing to causal mechanisms as 'mechanistic', despite these generally having nothing to do with classic mechanistic explanations. Mechanistic explanations are ones in which wholes are accounted for in terms of the structure and interactions of their parts. Thus, to explain a system mechanistically is to explain it as one explains a machine mechanism; i.e., to explain the way in which the component parts of the system determine the properties and activities of the whole. However, it is increasingly the case that philosophers employ the term 'mechanistic' simply as a synonym for 'causal' when characterizing scientific explanations. This is regrettable because it blurs the longstanding tradition in biology of using 'mechanistic' to refer to the ontological and epistemological commitments of mechanicism (such as in the title of Jacques Loeb's seminal manifesto, The mechanistic conception of life), which remain at the heart of contemporary disciplines like molecular biology. ${ }^{3}$ Consequently, for the sake of consistency it would be preferable to avoid the term 'mechanistic' altogether in discussions of causal mechanisms. In place of Skipper and Millstein's misleading banner, I will hereafter refer to the new mechanism movement in the philosophy of science as the mechanismic program, and to explanations given in terms of causal mechanisms as mechanismic explanations, retaining the word 'mechanistic' for discussions of mechanicism and machine mechanisms. This seems more appropriate, given that the term 'mechanismic' is already widely used in

\footnotetext{
${ }^{1}$ Interestingly, the machine mechanism and causal mechanism senses of 'mechanism' are sometimes invoked in the same context. For example, when biologists speak of 'the

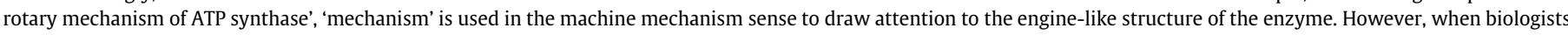

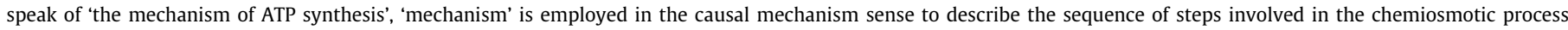
responsible for the generation of ATP.

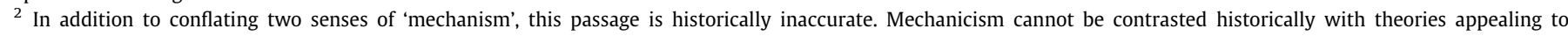

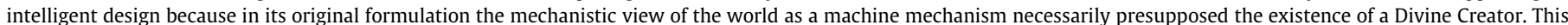

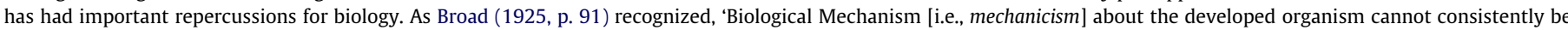

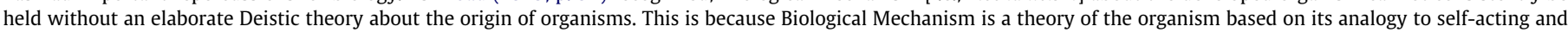

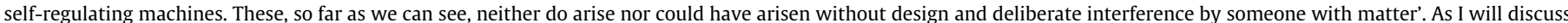
in the next section, it is only with the widespread acceptance of Darwin's theory of evolution that mechanistic biology became completely secularized.

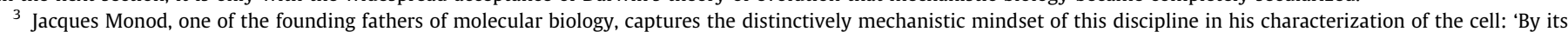

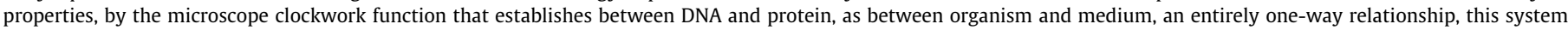
obviously defies 'dialectical' description. It is not Hegelian at all, but thoroughly Cartesian: the cell is indeed a machine' (Monod, 1977, p. 108).
} 


\section{Mechanicism (Mechanistic Philosophy) \\ examines \\ Machine Mechanisms \\ Mechanismic Program \\ examines \\ Causal Mechanisms}

Fig. 1. Relationship between the different meanings of 'mechanism'

philosophical discussions of causal mechanisms in the social sciences (e.g., Bunge, 1997; Falleti \& Lynch, 2009; Gerring, 2007; Norkus, 2005). ${ }^{4}$

\section{The conceptual evolution of 'mechanism' in biology}

Darden (2006, p. 289, fn. 5) has noted that 'The history of the usage of the concept of mechanism from the seventeenth century to molecular biology has yet to be written'. It would be impossible to provide a comprehensive account of this history in the present paper. Instead, I will restrict myself in this section to indicating what I take to be the critical episodes in that history which resulted in the semantic fragmentation of 'mechanism'.

The first two senses of 'mechanism' I distinguished, mechanicism and machine mechanism, can be traced back to the natural philosophy of the seventeenth century. Mechanicism in its first formulations was intertwined with natural theology, given that the mechanistic understanding of the universe as intricate clockwork (i.e., as a machine mechanism) necessarily implied a Divine Creator. As a result, all things in nature, including organisms, became conceived as complex assemblages of machinery created by an intelligent Designer. It is this mechanistic understanding of life which enabled the notion of machine mechanism to be employed beyond the realm of technological artefacts in explicitly biological contexts. For the mechanistic biologist, living systems are not just composed of machine mechanisms; they are themselves machine mechanisms. Indeed, allusions to the 'mechanism of the body' are commonplace throughout the history of physiology.

With Charles Darwin's theory of evolution by natural selection, it became possible to naturalistically explain the complex adaptations of organisms without needing to appeal to a Divine Creator. One of the implications of Darwin's theory was that its evolutionary understanding of organisms seemed to be at odds with the engineering-based conception of life of mechanicism, exemplified by its postulation of biological machine mechanisms. Therefore, to uncover the semantic evolution of the concept of mechanism, it is necessary to consider two key questions:

(a) What happened to the notion of machine mechanism in biology after Darwin?

(b) When and why did the notion of causal mechanism become pervasive in biology?

Ruse (2005) has actually provided answers to both of these questions, but his answers are problematic. In response to question (a), Ruse presents textual evidence which suggests that although Darwin did occasionally refer to biological machine mechanisms, unlike earlier biologists he always understood these machine mechanisms in a purely metaphorical sense. Ruse concludes from this that Darwin was responsible for demoting the notion of machine mechanism in biology to a heuristic status. With Darwin, machine mechanisms lost their ontic basis and became reconceptualized as heuristic tools that aid the investigation of adaptation. Darwin himself made use of the machine mechanism-heuristic in his inquiry into the workings of barnacles and orchids, and this remains a common practice in evolutionary biology, where it is known as 'reverse engineering'.

Although this account seems reasonable, a more careful examination reveals its problems. Despite the apparent incompatibility between the mechanistic conception of organisms as machines and a Darwinian understanding of organisms, what we actually find when we inspect modern evolutionary biology is that mechanistic language is not used exclusively at a heuristic level. Contrary to Ruse's expectations, Darwin did not strip the notion of machine mechanism of its ontic significance. Rather, it was evolutionary biology itself which adapted to accommodate mechanistic thinking about organisms, so that since Darwin, 'the idea that the world is full of designed machines has been replaced by the idea that it contains evolved machines' (Craver \& Darden, 2005, p. 239, my emphasis). In fact, Gould and Lewontin's (1979) famous critique of adaptationism can be interpreted precisely as a reaction against this excessive reliance on mechanistic thinking in evolution, which all too often constitutes not just a heuristic tool but also a theoretical justification for understanding organisms as optimallydesigned machines blindly engineered by natural selection (e.g., Dawkins, 1986; Dennett, 1995).

Moving to other areas of contemporary biology, it quickly becomes apparent that talk of machine mechanisms remains entrenched at an ontological level. In molecular and cellular biology, for instance, the standard conception of the organism is that of a machine programmed by its genes and decomposable into its component machine mechanisms. Subcellular protein complexes are frequently referred to as machines, and the cell itself is conceived as an assemblage of machine subunits (e.g., Alberts, 1998). An important point, however, is that despite the fact that machine mechanisms continue to play a fundamental role in many areas of biology, the term 'mechanism' is generally no longer used to designate them. Instead, biologists today tend to refer to machine mechanisms simply as 'machines', presumably to distinguish this notion from the sense in which 'mechanism' is now most commonly used in biology, namely causal mechanism.

Ruse's explanation for the displacement of machine mechanism by causal mechanism as the most widely used sense of 'mechanism', i.e., his answer to question (b), is also problematic. He suggests that Darwin's secularization of mechanicism enabled the concept of 'mechanism' to acquire widespread currency in the broader sense of causal mechanism. With Darwin, 'mechanism' came to be used to designate a much wider range of biological phenomena, including Darwin's own 'mechanism' of natural selection. However, after thoroughly searching through Darwin's works, Ruse actually discovers that Darwin 'simply does not speak of natural selection as a mechanism' (Ruse, 2005, p. 291). Darwin only uses 'mechanism' in the machine mechanism sense; the very idea of a causal mechanism is simply alien to him. As Ruse himself indicates, it is not until the late nineteen-thirties that natural selection came to be generally referred to as a 'mechanism'. Neither Fisher (1930) nor Haldane (1932) used this language, but Dobzhansky (1937) did, noting that 'the theory of natural selection is primarily an attempt to give an account of the probable mechanism [i.e., causal mechanism] of the origin of the adaptations of organisms to their

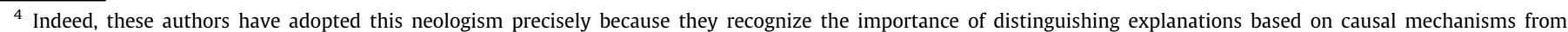

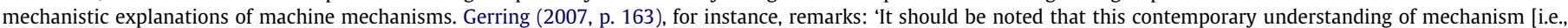

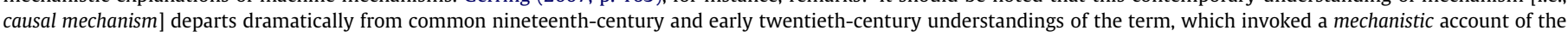

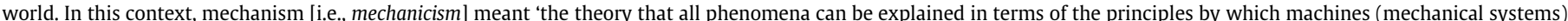

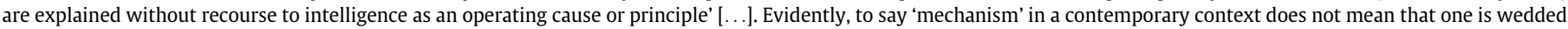
to a mechanistic causal account modelled on Newtonian physics'.
} 
environment' (Dobzhansky, 1937, p. 150). If Darwin's secularization of mechanicism truly brought about the widespread use of 'mechanism' in the causal mechanism sense, why is it that threequarters of a century had to pass from the publication of Darwin's Origin of species for natural selection to be commonly referred to as a 'mechanism'?

In light of these difficulties, I want to suggest a rather different answer to question (b). When considering the factors that had the greatest impact on mechanicism in the late nineteenth and early twentieth centuries, far more important than the advent of Darwinism was the gradual erosion of vitalism. As the philosophical antithesis of mechanicism, vitalism can be characterized as the doctrine that upholds the direct inverse of the four core tenets of mechanicism outlined in Section 2. The heart of the vitalistic doctrine is the postulation of a vital principle (which, depending on the historical period, assumed the form of a soul, a force, or a mode of organization) that ontologically demarcates living from non-living systems. From the seventeenth century onwards, mechanicism and vitalism developed in parallel, with the mechanists continually disproving the claims of the vitalists, and the vitalists repeatedly re-emerging to pose new challenges to the mechanists. However, by the late nineteenth century the spectacular empirical success of mechanicism in disciplines as diverse as physiology, developmental biology, and biochemistry ultimately led to the marginalization of vitalism as a workable research program. No longer being confronted by serious opposition, the mechanistic conception of life became widely accepted as an elementary presupposition of biological research in the early decades of the twentieth century. 'At the present day', wrote the embryologist Joseph Needham in 1925, 'the situation is in effect the complete triumph of mechanistic biology. It is not alone in the field, because the neovitalists do exist as a small minority, but the vast preponderance of active biological workers are mechanists' (Needham, 1925, p. 235).

I want to argue that one of the key consequences of the consolidation of mechanicism was that it was no longer necessary to explicitly defend the core tenets of this doctrine. The view that living systems are machines did not need to be justified and could simply be taken as a given. As a result, mechanism-talk became applied to all kinds of biological phenomena, given the mechanistic confidence that everything would, in due course, be explained as effectively as engineers explain the operation of machines. This increasingly loose use of 'mechanism' caused the word to gradually lose its distinctive mechanistic connotations, becoming a 'dead metaphor' that could be readily applied beyond the realm of machine-like systems to any biological phenomenon in need of a causal explanation. It is this semantic shift, I suggest, which led the term 'mechanism', understood in the more general and inclusive sense of causal mechanism, to acquire such widespread currency in biology.

Evidence for this account can be found by inspecting the writings of the biologists of this period. For example, J. S. Haldane, one of the most influential physiologists of the early twentieth century, drew attention on several occasions to the increasing proliferation of mechanism-talk in biology, pointing out that using the term 'mechanism' with respect to a phenomenon no longer implied conceiving it mechanistically as a machine mechanism. In The sciences and philosophy, he observed that 'In current physiological literature it is still customary, in describing what is known as to different bodily activities, to refer to them as 'mechanisms'for instance, the 'mechanisms' of reproduction, respiration, secretion, etc.' despite the fact that 'There are perhaps few physiologists who now consider that they have any real conception of these mechanisms [as machine mechanisms]'. The usage of 'mechanism', Haldane noted, has become 'a mere matter of custom' (Haldane, 1929, p. 59). In The philosophical basis of biology, Haldane reiterated these remarks, indicating that physiologists 'have acquired the habit, almost unconscious, of referring to the 'mechanisms' of various physiological activities, though they have not the remotest conception of what sort of mechanisms [i.e., machine mechanisms] these activities represent'. He concluded from this that 'the use of the word 'mechanism' is a mere empty formality' (Haldane, 1931, p. 11). Although Haldane openly voiced his concern regarding this looser use of 'mechanism' in the causal mechanism sense, warning that 'such a mode of expression is extremely misleading to that miscellaneous body which we call the public' (Haldane, 1929, p. 59), he clearly did not succeed in persuading his contemporaries against this usage of the term. Still, what is relevant in the present discussion is that his remarks lend credence to my proposed explanation of the supplantation of machine mechanism by causal mechanism as the most common meaning of the term in biology. ${ }^{5}$

\section{The mechanismic program in relation to mechanicism}

So far I have argued that due to the success of mechanicism in the early twentieth century, the causal mechanism sense of 'mechanism' became predominant in biology during this period, and remains so to this day. But how and when did the different senses of 'mechanism' come to be featured in the philosophy of biology? Exploring this question will help situate the recent mechanismic program in relation to mechanicism. This will be a key step in the development of my argument, as showing the fundamental differences between these two research programs will provide the basis for my critical engagement with the mechanismic program in Sections 5 and 6.

The longstanding conflict between mechanists on the one side and vitalists and organicists on the other, being in the final analysis a dispute concerning the very nature of life itself, constituted the central theme in the philosophy of biology during the first half of the twentieth century (see Bertalanffy, 1952; Johnstone, 1914; Woodger, 1929), even if by this time most experimental biologists (like Needham) considered that the dispute had already been resolved in favour of mechanicism. Mechanistic biology and machine mechanisms continued to be discussed in subsequent decades (e.g., Varela \& Maturana, 1972), capturing even the attention of leading exponents of logical empiricism like Hempel (1966, ch. 8) and Nagel (1979, ch. 12). However, following the academic institutionalization of the philosophy of biology at the hands of David Hull, Michael Ruse and others, discussions of mechanistic biology came to an abrupt end as the new generation of philosophers of biology, influenced by philosophically-minded evolutionists like Ernst Mayr, turned its attention to theoretical issues in evolutionary biology, such as the levels of selection, the definition of fitness, and the nature of species. Nevertheless, critical examinations of mechanistic biology and machine mechanisms are still featured in the contemporary literature (e.g., Dupré, 2007; Lewens, 2004; Lewontin, 2000; McLaughlin, 2001; Rosen, 1991), although the terms in which the issues are discussed have changed somewhat.

What of the third sense of 'mechanism'? When did causal mechanisms enter into philosophical discussions of biology? Browsing the literature one finds references to the term 'mechanism' employed in the causal mechanism sense in articles by Kauffman (1970), Grene (1971) and Wimsatt (1972, 1974). However, Brandon (1985) appears to have been the first to provide a

\footnotetext{
${ }^{5}$ It is interesting to note that the causal mechanism sense of 'mechanism' first began to permeate the literature on natural selection only a few years after Haldane's warnings against this looser use of the term (see Ruse, 2005)
} 
detailed analysis of the importance of causal mechanisms in biological research. Brandon's account is important for several reasons. For one thing, it is the first to explicitly recognize the semantic ambivalence inherent in the biological usage of 'mechanism', as well as the inevitable difficulties that arise when attempting to pin down this concept. ${ }^{6}$ More crucially, it presents an understanding of the postulation of causal mechanisms in science that distinctly characterizes the mechanismic program today, namely that the appeal to causal mechanisms in scientific practice does not imply a commitment to the reductionistic agenda of mechanicism. ${ }^{7}$ Indeed, whereas mechanicism, as Craver and Darden (2005, p. 235) note, is 'closely aligned with the spirit of reductionism and the unity of science', the mechanismic program focuses on multi-level explanations given in terms of causal mechanisms and with an explicitly non-reductive view of science (see Craver, 2005; Darden, 2005).

The mechanismic program, unlike mechanicism, is not primarily concerned with biological ontology, but with the nature of biological explanations. This is not surprising given that the postulation of causal mechanisms, having become a virtually ubiquitous practice in contemporary biology, discloses rather little about a biologist's ontological commitments. Physiologists, ecologists, neuroscientists, and cell biologists have different understandings of life, yet they all appeal to causal mechanisms in their explanations. Clearly, whatever ontological commitments they all share are likely to be very general in nature. This stands in contrast with molecular biologists' standard mechanistic conception of living systems as machine mechanisms, for which explanations are sought from the bottom up in increasing levels of complexity. In every respect, the appeal to machine mechanisms is indicative of far more substantive ontological commitments than the appeal to causal mechanisms. These ontological commitments (summarized in Section 2) are at the heart of the mechanistic conception of life that dominated biological thought for much of the twentieth century, but which today, with the growing emphasis on systemic thinking in biology, is increasingly viewed as simply one of several possible understandings of what living systems are and how they should be studied.

In the few occasions when mechanismic philosophers explicitly address matters of biological ontology, it is usually to distinguish the mechanists' appeal to machine mechanisms from their own concern with causal mechanisms (recall Fig. 1). By demarcating causal mechanisms from machine mechanisms, mechanismic philosophers distance their research program from the ontological commitments of mechanicism. Mechanismic philosophers distinguish causal mechanisms from machine mechanisms in two ways. The first strategy (which I already alluded to in the Introduction) is to focus on the way the term 'mechanism' is presently used in biology and disregard older uses of the term as irrelevant to current analyses of the concept (e.g., Craver, 2007, p. 3). What this does is minimize the scope for conflating the older biological usage of 'mechanism' in the machine mechanism sense (predominant in biology until the first third of the twentieth century) with the current biological usage of the term in the causal mechanism sense. The second strategy is to explicitly differentiate 'mechanisms' (i.e., causal mechanisms) from 'machines' (i.e., machine mechanisms), and both Darden (2006, pp. 280-281; 2007. p. 142 ) and Craver (2007, p. 4 and p. 140) do this on more than one occasion.
It is important to realize the extent to which MDC's (2000) account of causal mechanisms has marked a turning point in philosophical discussions of this concept. Before MDC's account, characterizations of 'mechanisms' routinely conflated the machine mechanism and causal mechanism senses. For instance, Thagard (1998) noticed that the term 'mechanism' is commonly featured in contemporary explanations of disease, but defined it in the machine mechanism sense as 'a system of parts that operate or interact like those of a machine' (p. 66, my emphasis). Similarly, when Glennan first defined 'mechanism', he indicated that his definition is meant to apply to 'complex systems analogous to machines' (Glennan, 1996, p. 51, my emphasis). In fact, Glennan has continued to heavily rely on the notion of machine mechanism in his account of 'mechanisms', going as far as to cite cells and organisms as prime examples of his conception of them (Glennan, 2002, p. S345). Although mechanistic biologists do indeed ontologically conceive cells and organisms as machine mechanisms, it makes little sense for any biologist to consider the causal mechanism of an entire cell or organism. Most mechanismic philosophers would disagree with Glennan's designation of cells and organisms as 'mechanisms', and the reason is clear. The new mechanismic program 'strives to characterize mechanism [...] in a manner faithful to biologists' own usages' (Darden, 2007, p.142) and causal mechanism is what most present-day biologists mean when they use the word 'mechanism'. This is why mechanismic philosophers focus exclusively on this sense of the term, and why most of them would not recognize supposed machine mechanisms like cells and organisms as 'mechanisms'.

The reason for Glennan's apparent unconcern regarding the lack of correlation between his mechanistically tinged understanding of the concept of 'mechanism' and the way the term is actually used by most contemporary biologists is that his account of mechanisms is not primarily motivated by an interest in scientific practice (like MDC and others), but by a concern with the nature of causation. Indeed, in his 1996 paper Glennan sets out to address Hume's sceptical challenge regarding the connection between cause and effect by suggesting that 'mechanisms' could provide a plausible metaphysics of causation. Glennan proposes that events are causally related if there is a 'mechanism' that connects them, and he uses this conception of 'mechanism' to develop a mechanical view of explanation (Glennan, 2002). In doing so, Glennan builds on Salmon's (1984) account of causal-mechanical explanation, which was itself an elaboration of Railton's (1978) deductive-nomological model of probabilistic explanation, in which the term 'mechanism' was introduced into the philosophical literature on scientific explanation (Glennan 2002, p. S343). Interestingly, this earlier work on 'mechanisms', unlike the more recent biologically-inspired mechanismic discourse, does actually show some clear links with mechanicism. Railton (1978) says the following regarding his mechanistic orientation:

The goal of understanding the world is a theoretical goal, and if the world is a machine [...] then our theory ought to give us some insight into the structure and workings of the mechanism [i.e., machine mechanism], above and beyond the capability of predicting and controlling its outcomes. (Railton, 1978, p. 208, my emphasis)

This conception of the world as a machine mechanism, as well as the stated desire to understand, predict, and control it, are all

\footnotetext{
${ }^{6}$ Indeed, when Brandon asks what mechanisms are, he is unable to provide a precise definition. He notes that 'mechanism' may refer to 'spring-wound clocks and watches' (i.e.,

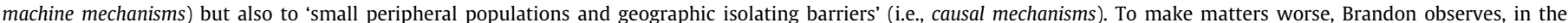

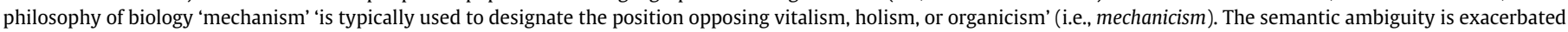

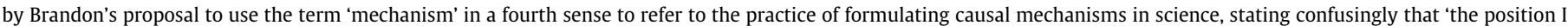
call mechanism is given in terms of search of mechanisms' (Brandon, 1985, p. 346).

7 Brandon further develops this important thesis in a more recent essay entitled 'Reductionism versus holism versus mechanism' (Brandon, 1996, ch. 11).
} 
characteristic attributes of mechanistic philosophy. Along similar lines, Glennan points out that his account of 'mechanisms' is 'largely inspired by the insights of the Mechanical philosophers' of the seventeenth century' (Glennan, 1996, p. 51). Thus, Skipper and Millstein's (2005) banner of 'the new mechanistic philosophy' would have been far more appropriate if it had been used to refer to this literature on 'mechanisms', rather than to the more recent examinations of causal mechanisms in biology, which on the whole bear little connection to the original motivations of this earlier work in the philosophy of science. Darden's latest appraisal of the mechanismic program makes this explicit when she clarifies that 'work on mechanisms in biology originated (primarily) not as a response to past work in philosophy of science but from consideration of the work of biologists themselves' (Darden, 2008, p. 958).

Overall, it is clear that the mechanismic program must be regarded as being completely independent from mechanicism, both as a general doctrine and specifically as it applies to biology. Indeed, we have seen how leading proponents of the mechanismic program like Craver and Darden reject some of the core tenets of mechanicism, such as the reducibility of biology to physics and chemistry, and the exclusive reliance on reductionistic explanations. Demarcating the mechanismic program from mechanicism is crucial, as the failure to do so results in problematic analyses of causal mechanisms. The most glaring example of this, in my view, is found in some of Bechtel's recent work. While most mechanismic philosophers are rather cautious in their use of history when discussing causal mechanisms, drawing on relatively recent case studies when illustrating their claims, Bechtel traces the appeal to 'mechanisms' in scientific explanation not just to Descartes in the seventeenth century, but all the way back to the Ancient Greek atomists of the fifth century BCE (Bechtel, 2006, pp. $20-21 ; 2008$, p. 10). But instead of considering how the meaning of 'mechanism' has developed over time (as Ruse (2005) does, and as I have attempted to do in Section 3), Bechtel just takes the modern sense of 'mechanism' as causal mechanism as his starting point and then simply projects it back in history. As a result, his historical discussions conflate the distinctive appeal to machine mechanisms by mechanistic biologists with the almost ubiquitous appeal to causal mechanisms by biologists today (e.g., Bechtel, 2006; 2007, ch. 2). Understanding the term 'mechanism' exclusively in the causal mechanism sense, Bechtel complains that critics of mechanistic biology commit a grave mistake in assimilating the notion of 'mechanism' to that of machine (Bechtel, 2008, p. 2), not realizing that the very reason for this is that when mechanists do speak of 'mechanisms', machine-like systems (i.e., machine mechanisms) is precisely what they have in mind. ${ }^{8}$

The striking thing is that Bechtel, just like Craver and Darden, actually rejects central tenets of mechanistic biology, such as the exclusive reliance on explanatory reductionism (Bechtel \& Abrahamsen, 2008), and the privileging of the efficient and material causes of organisms over and above their systemic, self-organizing properties (Bechtel, 2007). But, again, instead of distancing himself from mechanicism, Bechtel seems to think that the only way to make sense of the pervasiveness of mechanism-talk in current biology is to broaden the doctrine of mechanistic biology accordingly, not realizing that the appeal to the term 'mechanism' in sci- entific practice today no longer commits one to mechanicism (as 'mechanism' is now generally employed in the causal mechanism sense). This leads Bechtel to formulate a very odd conception of mechanistic biology, so general in content and inclusive in its applicability that none of the distinctive ontological and epistemological commitments that tend to be associated with it (see Section 2) are relevant. Instead, all that qualifies a biologist as a 'mechanist' for Bechtel is that she appeals to 'mechanisms' in her research. Similarly, all that qualifies an explanation as 'mechanistic' is that a 'mechanism' is featured in it, regardless of the way in which this concept is used. ${ }^{9}$

I can think of two reasons for Bechtel's misrepresentation of mechanicism. The first is that some of his earlier work (e.g., Bechtel \& Richardson, 1993) was in fact concerned with mechanistic explanations in biology, specifically with the strategies of decomposition and localization that are often featured in them. ${ }^{10}$ So in the wake of the influence of MDC's (2000) account of causal mechanisms, Bechtel might have felt it natural to bridge his earlier discussion of machine mechanisms with an examination of causal mechanisms, since, after all, the term 'mechanism' is central to both discourses. Still, the main reason for Bechtel's misrepresentation is that he does not appear to recognize that the concept of 'mechanism' has more than one meaning. It is because he conflates the notions of machine mechanism and causal mechanism that he also conflates mechanicism with the mechanismic program (e.g., Bechtel, 2006, ch. 2; 2008, ch. 1).

Nevertheless, the mischaracterization of mechanicism is not the only, or even the main, problem that results from the conflation of causal mechanisms and machine mechanisms. The most serious consequence of not distinguishing these notions is that causal mechanisms become inappropriately endowed with the ontic status of machine mechanisms. This ontologization of causal mechanisms is very widespread in the philosophical literature, and in the next section I will discuss some of the problems that stem from it.

\section{Problems resulting from the ontologization of causal mechanisms}

Mechanismic philosophers tend to conceive causal mechanisms as real things in the world existing independently from our conceptualization of them. However, based on the role they play in scientific practice, I suggest that causal mechanisms are better understood as heuristic models that facilitate the explanation of phenomena. The fact that the overwhelming majority of mechanismic philosophers speak of them as 'real systems in nature' (Bechtel, 2006, p. 33) I attribute to an inadvertent transposition of the ontic status of machine mechanisms (the original sense in which 'mechanism' was used) onto the notion of causal mechanism (the standard meaning of 'mechanism' in biology today). This ontologization of causal mechanisms tends to result in a conception of them as autonomous complex systems (analogous to machine mechanisms), which constitute and operate within the organism (e.g., Bechtel, 2007; Glennan, 2002). I maintain that this ontic conception of causal mechanisms is problematic, and I will substantiate this claim by examining what are perhaps the two

\footnotetext{
8 This is as true for seventeenth-century mechanists like Descartes as it is for twentieth-century mechanists like Loeb.

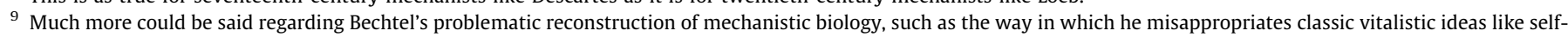

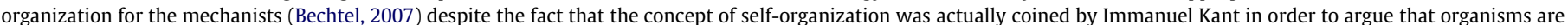

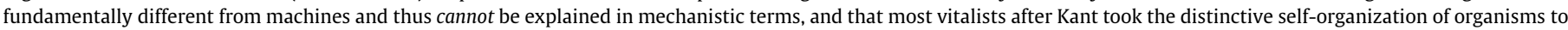
constitute the principal manifestation of the vital principle they postulated. However, elaborating these claims would take me beyond the scope of this paper.

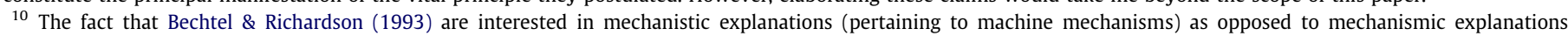

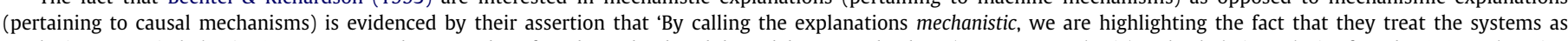

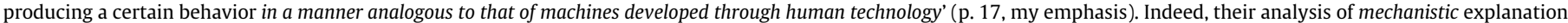

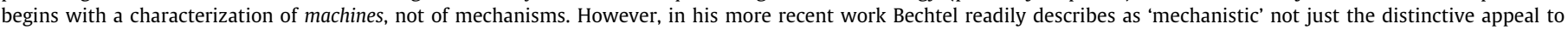
machine mechanisms by mechanists, but also the widespread appeal to causal mechanisms in current scientific practice.
} 
most distinctive features of causal mechanisms in biology: function and organization (cf. McKay \& Williamson, 2010).

\subsection{Function}

The operation of a causal process described in a causal mechanism produces a particular phenomenon that serves to individuate and causally relate the entities and activities that are responsible for it. In biology, the phenomenon produced by the causal process described in a causal mechanism usually enables the fulfilment of a function, so that specifying the causal mechanism for a function explains how this function is causally brought about. The problem of conceiving causal mechanisms as autonomous complex systems is that it overlooks the conditions that actually enable the functions of these systems to be carried out, as well as the true biological significance of those functions.

A living organism is an organized network of processes of production, transformation, and regeneration of components that continuously realizes itself by means of the coordinated orchestration of the components that make it up (Maturana \& Varela, 1980). In this way, the organism constitutes an integrated whole which maintains its identity through time by regulating, repairing, and reproducing its component parts. These parts stand in a relation of collective interdependence, as every one of them is necessary for the generation and operation of every other. Thus the attribution of functions to the parts of an organism is dictated by the means in which each part individually contributes to the maintenance and organization of all other parts and hence to the organism as a whole (see Edin, 2008; McLaughlin, 2001; Mossio, Saborido, \& Moreno, 2009). This means that the function of all suborganismic systems and processes featured in causal mechanisms is ultimately that of preserving the autopoietic organization of the whole organism.

The idea of autonomous causal mechanisms operating within the organism is, I suggest, nothing more than a pragmatic idealization that biologists appeal to in order to narrow their focus on the particular parts of the organism they happen to be investigating. This heuristic fragmentation of the organism into causal mechanisms, despite being necessary for its investigation, often comes at the expense of neglecting the way in which the organism as a whole influences the behaviour of its parts. In current philosophical accounts, the ontic conception of causal mechanisms as real autonomous subsystems neglects the fact that in order to make appropriate biological sense of the subsystems' functions, these subsystems need to be framed within a set of background conditions, that is, the organismic context that enables them to carry out their functions in the first place. ${ }^{11}$

Craver (2007, p. 122) has indicated that 'The core normative requirement on mechanistic [i.e., mechanismic] explanations is that they must fully account for the explanandum phenomena'. That is, 'Good explanations account for all of the features of a phenomenon rather than a subset' (ibid., p. 161). This means that mechanismic explanations that do not include a full account of the organismic context that enables the production of the explanandum phenomenon (or function) are, on Craver's terms, necessarily incomplete. This is problematic as actual scientific practice demonstrates that mechanismic explanations are never exhaustive catalogues of all the causal relations necessary for the production of phenomena, such as the enabling conditions provided by the organism as a whole. Rather, mechanismic explanations specify only those features of the underlying causal networks that biologists deem most relevant for manipulating and controlling the phenomena whilst at the same time presupposing a great deal of the organismic context that makes them possible. For this reason, it makes more sense to view causal mechanisms as idealized spatiotemporal cross-sections of organisms that heuristically pick out certain causal features over others in order to account for how given functions within the organism are carried out, as these are generally the things that biologists describe when they use the term 'mechanism' in their explanations.

\subsection{Organization}

Mechanismic philosophers frequently emphasize the importance of organization for understanding how causal mechanisms account for functions or behaviours. MDC (2000, p. 3), for instance, state that 'The organization of entities and activities determines the ways in which they produce the phenomenon'. Bechtel (2006, p. 26) similarly notes that 'The orchestrated functioning of the mechanism is responsible for one or more phenomena'. The problem is that mechanismic philosophers do not actually explain how the entities and activities in a mechanism are organized, only that they are organized. $\operatorname{MDC}(2000$, p. 3$)$ point out that 'Entities often must be appropriately located, structured, and oriented, and the activities in which they engage must have a temporal order, rate, and duration' but say nothing about the means by which these crucial organizational requirements are actually met in living organisms. Instead, all that discussions of organization in the mechanismic literature amount to is the plain assertion that organization matters (e.g., Craver, 2007, pp. 134-139).

Still, if causal mechanisms are to be conceived ontically as real suborganismic systems (rather than epistemically as idealized models of those subsystems, as I suggest) then just paying lip service to the fact that these subsystems are organized is insufficient. To fully account for the explanandum phenomenon (Craver's normative requirement for a good mechanismic explanation) it becomes necessary not just to specify, but also to explain how this organization is generated and maintained. The problem is that this requires taking the description beyond the actual causal mechanism to the level of the organism as a whole, given that suborganismic parts do not organize themselves but rely on the action of the whole organism for their generation, organization, and maintenance. This is rarely understood in mechanismic accounts of organization. For example, when Craver (2007, p. 148) indicates that a 'mechanism might compensate for the loss of a part by recovering (healing the part), by making new use of other parts, or by reorganizing the remaining parts', he is inappropriately attributing actions to an ontologized causal mechanism that are actually performed by the organism which contains it. $^{12}$

As I have argued in my discussion of function, one of the advantages of understanding causal mechanisms as idealized models of suborganismic causal processes rather than as real things is that a satisfactory mechanismic explanation need not include an account of how the target system is actually organized by the organism even if this organization is strictly speaking necessary for the system to causally bring about the phenomenon. This is more in

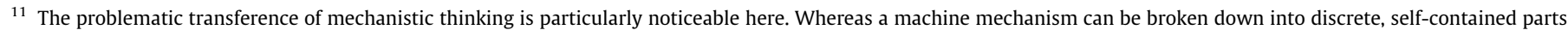

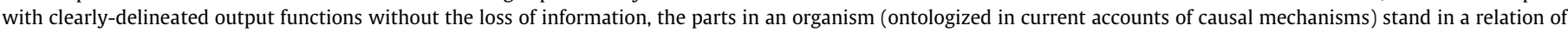

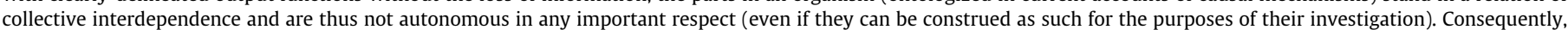

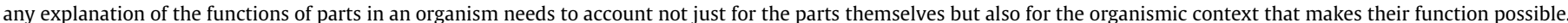

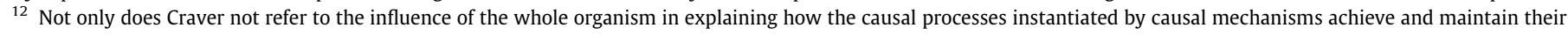

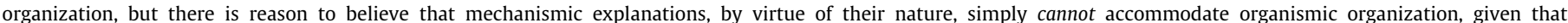

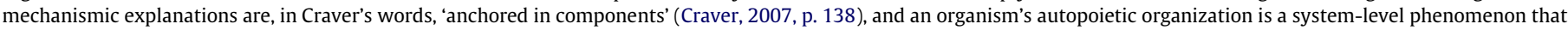
is not explainable by attending exclusively to the properties of component parts.
} 
accordance with actual scientific practice, in which causal mechanisms tend to pragmatically abstract away the organismic context and only specify the causal features that are taken to be most relevant for controlling and manipulating the phenomena being investigated. In the next section, I will elaborate and defend the epistemic account of causal mechanisms, indicating the further advantages of this view over the ontic conception that most mechanismic philosophers presently favour.

\section{Defending an epistemic conception of causal mechanisms}

It is important to keep in mind that the causal mechanism sense of 'mechanism' was not formulated in abstracto and then applied to scientific practice. Rather, it arose from scientific practice and it has only recently been philosophically reconstructed to make sense of how scientists explain phenomena. Consequently, the success of any given philosophical reconstruction of 'mechanism' must be measured in terms of how well it captures the way this term is used in scientific practice. The conception of causal mechanism that I argue best fits biologists' mechanism-talk is that of a contingent explanatory description which heuristically abstracts away the complexity of a living system sufficiently to describe some localized causal process within it which leads to the realization of some function of interest. That is, causal mechanisms are epistemic models that enable the explanation of how phenomena are causally brought about.

Interestingly, although most mechanismic philosophers claim to uphold an ontic view of causal mechanisms, much of what they say is actually perfectly compatible with an epistemic conception. In fact, it is not difficult to find instances in the philosophical literature in which ontically construed causal mechanisms are conflated with their epistemic representations, as I will show in a moment. This ambiguity, I suggest, is the result of the tension that inevitably arises from inappropriately transposing the ontic status of machine mechanisms onto causal mechanisms on the one hand, and paying close attention to the role that mechanism-talk actually plays in scientific practice on the other.

When scientists inquire about the causal mechanism of $\mathrm{P}$ (where $\mathrm{P}$ is the phenomenon of interest), the term 'mechanism' does not refer to that which is explained but rather to that which does the explaining. Craver (2007) acknowledges this when he asserts that 'The explanans is a mechanism' (p. 139) and the phenomenon of interest is the explanandum (p. 6). ${ }^{13}$ In this way, specifying a causal mechanism for a phenomenon implies providing an explanation for it. As MDC indicate, 'Mechanisms are sought to explain how a phenomenon comes about or how some significant process works' (2000, p. 2, my emphasis). One of the advantages of the epistemic view of causal mechanisms is that it is no longer necessary to postulate additional epistemic notions like 'mechanism sketch' and 'mechanism schema' to make sense of mechanismic explanations. Depending on the degree of abstraction, causal mechanisms may constitute what mechanismic philosophers call 'sketches', 'schemas', or 'mechanisms'. Craver (2007, p. 114) tacitly admits the continuity between these notions when he indicates that progress in formulating a successful mechanismic explanation 'involves movement [...] along the sketch-schema-mechanism axis'.

Moreover, the very characterizations of causal mechanisms that mechanismic philosophers have proposed are in fact perfectly compatible with an epistemic understanding of them. According to the epistemic view, causal mechanisms constitute idealized representations of causal processes. These causal processes are abstracted temporally and spatially. Temporally, the causal mechanism delimits a particular causal process by specifying arbitrary beginning and end points that are selected on pragmatic grounds. MDC (2000, p. 11) explicitly recognize that the set-up and termination conditions of causal mechanisms are 'idealized states', and Darden has reiterated this point on several occasions, noting that the beginning and end points of causal mechanisms are 'more or less arbitrarily chosen' (Darden, 2007, p. 141; see also Torres, 2009, p. 240, fn. 10). So although MDC purport to uphold an ontic conception of causal mechanisms, they actually characterize them in terms of epistemically selected beginning and end points.

Causal mechanisms are also abstracted spatially, according to the epistemic view, as they can only capture certain ontic features of reality at the expense of neglecting others. What gets represented and what is omitted in a causal mechanism is dictated by the nature of the explanandum phenomenon. Craver (2007, pp. 139-160) reaches this same conclusion when he considers the normative requirements that determine whether or not something is included as part of a causal mechanism, asserting repeatedly that the delimitation of causal mechanisms can only occur in the context of explanation. That is, entities, activities, and organizational features are part of the causal mechanism for $\mathrm{P}$ (where $\mathrm{P}$ is the phenomenon of interest) if and only if they are relevant to the explanation of $\mathrm{P}$. The act of individuating the causal mechanism for $P$ is thus the act of determining what aspects are causally relevant to the explanation of P. The delimitation of causal mechanisms hence 'depend[s] on the epistemologically prior delineation of relevance boundaries' (Craver, 2007, p. 144, my emphasis).

This view of causal mechanisms significantly departs from the ontic conception of them as autonomous systems akin to machine mechanisms (defended by Glennan, Bechtel, and at times by Craver himself, as shown in Section 5), given that the parts of a causal mechanism do not even need to be structurally demarcated. ${ }^{14}$ All that matters is that they are causally relevant to the production of the explanandum phenomenon. Craver fleshes out this notion of causal relevance by appealing to Woodward's (2003) manipulability theory of causation. In this way, a part is causally relevant to the phenomenon produced by a causal mechanism if one can modify the production of this phenomenon by manipulating the behaviour of the part, and one can modify the behaviour of the part by manipulating the production of the phenomenon by the causal mechanism.

Although Craver's account of explanatory relevance is compatible with both an ontic and an epistemic conception of causal mechanisms, there do not appear to be any obvious reasons for favouring the former over the latter view; if anything, the latter view seems more plausible. Explanations always presuppose a context that specifies what is to be explained and how much detail will suffice for a satisfying answer, and Craver recognizes that it is this very epistemic context that determines how causal mechanisms are individuated and what details are featured in them. The crucial requirement of any causal mechanism, according to Craver, is that it must capture the underlying causal relationships of the target system in such a way that it exhibits the necessary resources for explaining how the target system will behave as a result of interventions and manipulations of its parts. An epistemic view of causal mechanisms fulfils this requirement.

It may be helpful to illustrate these claims with an example. Consider the causal mechanism for the membrane trafficking of the delta-opoioid receptor (DOR) induced by pain stimulation, shown in Fig. 2 (adapted from Bie \& Pan, 2007). This causal mechanism exhibits all of the features I have discussed. It is a step-by-step explanation of the mode of operation of the signal transduction pathway induced by pain stimulation that triggers

\footnotetext{
13 Thus, mechanismic explanations should be understood not as explanations of causal mechanisms, but as explanations given in terms of causal mechanisms.

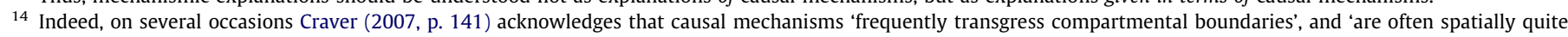
distributed' or 'tightly interwoven into their systematic context' (ibid., p. 143, fn. 23).
} 


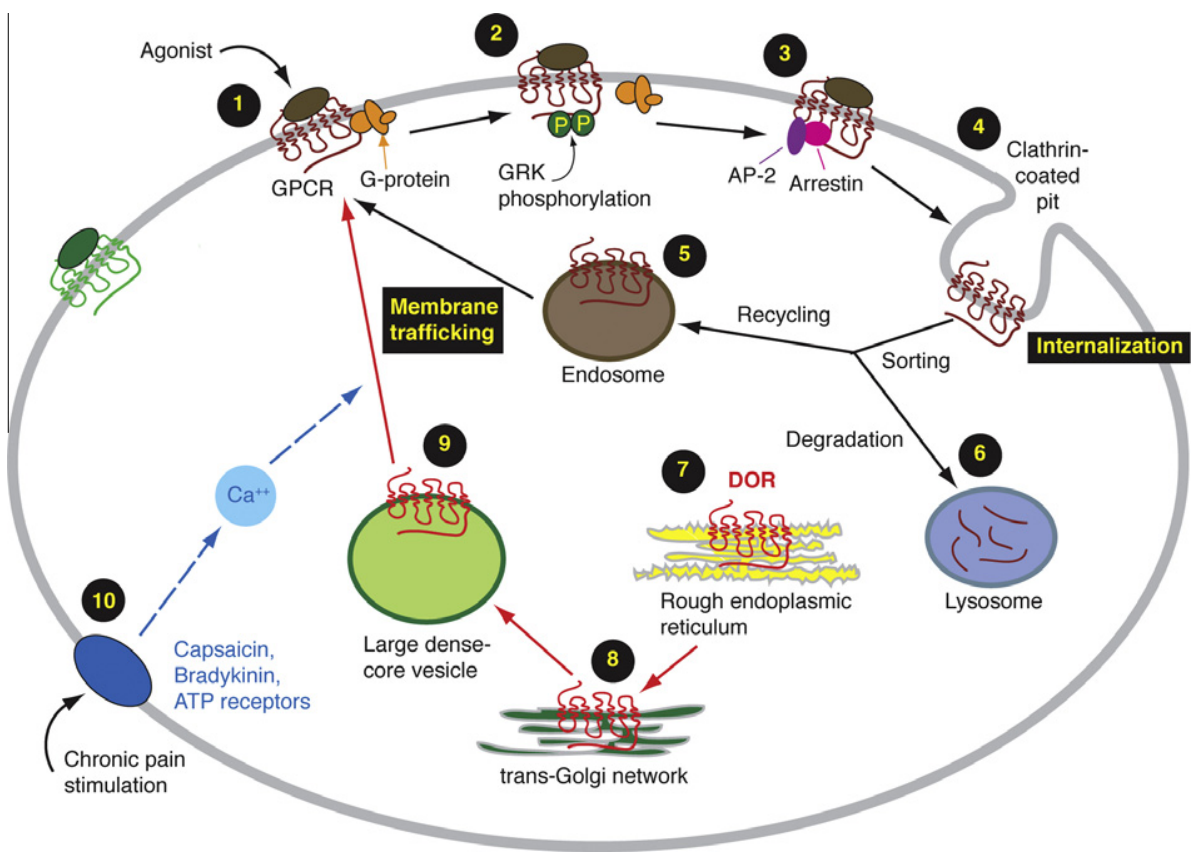

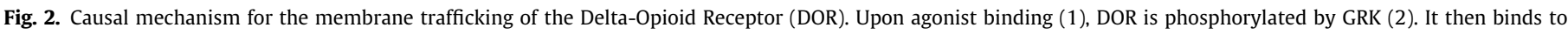

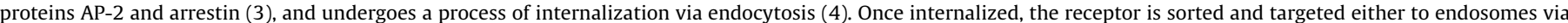

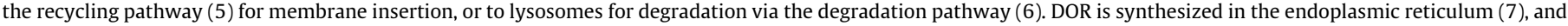

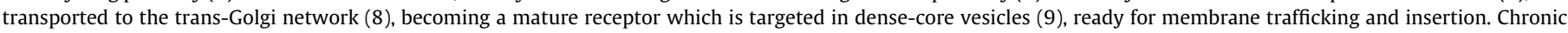
pain stimulation activates receptors (10) and increases intracellular calcium concentration, inducing the membrane trafficking of DOR.

the intracellular activation of DOR, which results in effective pain relief. The causal mechanism is abstracted both temporally and spatially. Temporally, it abstracts the continuous life-cycle of DOR into a series of discrete idealized stages, which are numbered in the causal mechanism. Spatially, although the whole cell is depicted, only the features that are causally relevant to the membrane trafficking of DOR (i.e., the explanandum phenomenon) are featured in the causal mechanism. What is represented in the causal mechanism is contingent on epistemic considerations given that if we happened to be interested in explaining any other cellular phenomenon, a different yet partially-overlapping set of features would be included in the causal mechanism. Moreover, the organismic context (in this case, the cell) is almost completely abstracted away and yet it is heavily presupposed, as it provides the enabling conditions that are ultimately necessary for the membrane trafficking of DOR. Finally, the causal mechanism constitutes an explanatory model of a particular cross-section of the cell that provides the necessary resources for anticipating how interventions and manipulations of any of the causally relevant parts within the cell and any of the successive stages of the described process will affect the membrane trafficking of DOR. In this way, this causal mechanism serves the heuristic purpose of aiding the physiological and pharmacological investigation of pain relief.

So far in this section, I have advanced my defence of an epistemic view of causal mechanisms by showing how the key features of causal mechanisms that mechanismic philosophers deem most important for understanding them are not only not incompatible with the epistemic account I propose, but actually provide strong support for it. Nevertheless, the compatibility of the central claims of MDC and others with an epistemic conception of causal mechanisms does not constitute the main incentive for adopting it. The major reason for defending an epistemic account, as I will argue in the remainder of this section, is that it captures the meaning of biologists' mechanism-talk in ways that are simply beyond the reach of any single ontic conception of causal mechanisms.
Causal mechanisms are invoked to explain an extremely wide range of phenomena. As Allen (2005, p. 264) indicates, causal mechanism 'can refer to very specific processes, such as the nucleophilic attack by the reactive group of an enzyme on an exposed covalent bond of its substrate, or to a whole category of reactions such as cell signal responses due to protein kinase A (PKA) second messengers'. As the postulation of causal mechanisms has become a virtually ubiquitous practice in biological research, it is practically impossible to define what a causal mechanism is in a way that meaningfully captures all the different uses of this notion, given that the conditions of satisfaction for what counts as a causal mechanism are entirely determined by the context in which it is postulated and on the kind of questions that are asked of the explanandum phenomenon. If, as I suggest, the notion of causal mechanism is understood epistemically, then it can be characterized as an explanation where the explanans and explanandum are sorted out from the context of its formulation. However, if causal mechanisms keep being conceived as 'real systems in nature' (Bechtel, 2006, p. 33), it becomes exceedingly difficult to specify exactly what these 'systems' actually are, not to mention what they all have in common.

Paradoxically, this problem stems from the mechanismic program's desire to closely adhere to scientific practice, given that as long as it remains 'faithful to biologists' own usages' of 'mechanism' (Darden, 2007, p. 142), it cannot fulfil its objective of ontically characterizing this notion in a concrete and unified manner. The reason for this is that there is an unavoidable trade-off between the degree of concreteness of any given ontic characterization of causal mechanisms and the breadth of its applicability. In other words, an ontic characterization of causal mechanisms can only increase its domain of applicability at the expense of sacrificing the concreteness of its formulation. Consequently, the only way mechanismic philosophers could encompass all the different ways in which the notion of causal mechanism is employed in scientific practice would be to propose an ontic characterization so general and so abstract that it would be effectively vacuous. 
The recent debate concerning the nature of the causal mechanism of natural selection provides an instructive illustration of this dilemma. Skipper and Millstein (2005) have convincingly argued that none of the major ontic conceptions of causal mechanism successfully captures 'the mechanism of natural selection'. The causal mechanism of natural selection is not composed of entities and activities organized to produce regular changes (á la MDC), nor is it a series of parts in a complex system interacting to produce a behaviour (á la Glennan), nor is it a structure performing a function in virtue of its component parts (á la Bechtel). The different ways in which mechanismic philosophers have dealt with this incompatibility is quite revealing. Glennan (2005b) bites the bullet and concludes that 'there is no such thing as the mechanism of natural selection'. This strategy is problematic because it is at odds with the mechanismic commitment to the 'details of scientific practice' (MDC, 2000, p. 2), given that evolutionary biologists do routinely refer to natural selection as a 'mechanism'. Craver and Darden (2005, p. 240) instead contemplate 'whether the account of mechanism should be broadened to allow for stochastic processes and other forms of organization'. Skipper and Millstein (2005, p. 344) also consider this option but decide against it because postulating such a broad conception of causal mechanism 'may not be desirable if it means sacrificing an understanding of the things that make mechanisms distinctive in particular fields, such as molecular biology'. This concern aptly illustrates the danger of vacuity that arises from formulating exceedingly broad ontic characterizations of causal mechanisms. Barros (2008) proposes a third solution, which is to formulate various ontic characterizations of causal mechanism, among them one which can effectively capture the causal mechanism of natural selection. The problem with this strategy is that it means giving up the objective of having a unified conception of causal mechanisms that can be used to make generalizations regarding the nature of mechanismic explanations across biology. In this way, all three proposed solutions are unsatisfactory. However, when we adopt an epistemic view of causal mechanisms, the tensions generated by the efforts to ontically reconstruct this causal mechanism disappear. ${ }^{15}$

Some mechanismic philosophers may object that the thesis that causal mechanisms are epistemic rather than ontic can be refuted on the grounds that biologists often use 'mechanism' to refer to the causal process itself and not (just) to the explanation of it. In response, I would argue that it is very important to understand why biologists use the term 'mechanism' in their research in the first place. The inadvertent conflation of the machine mechanism and causal mechanism senses is once again at the heart of the matter. Mechanismic philosophers tend to assume that using the term 'mechanism' in relation to $\mathrm{P}$ (where $\mathrm{P}$ is the phenomenon of interest) indicates something distinctive about the nature of $P$ that motivates and legitimates the use of the word 'mechanism' in the context of its explanation. Although this has indeed been the case in the past when mechanists conceived organisms and their parts as machine mechanisms, the ubiquitous appeal to 'mechanisms' by the majority of biologists today is no longer determined by the prescriptive ontological commitments of mechanicism, as I showed in Section 4. Mechanism-talk in contemporary biology is simply a contingent product of history, or as Haldane put it, 'a mere matter of custom'. Consequently, the use of the word 'mechanism' in an ontic sense by some biologists does not demonstrate that causal mechanisms need to be understood as real things. The ontic-epistemic dispute concerning the nature of causal mechanisms will not be settled by simply listing examples of the usage of 'mechanism' in the scientific literature, but by considering how best to make philosophical sense of the role played by mechanism-talk in scientific reasoning and explanation.

\section{Conclusion}

In this paper I have attempted to clarify the semantic confusion surrounding the concept of 'mechanism' as it is used in biology. I have argued that causal mechanisms-the targets of the new mechanismic program in the philosophy of biology-owe their ubiquity in contemporary biological explanations to the stunning successes of mechanistic investigations in the late nineteenth and early twentieth centuries. Historically, I have claimed that the mechanistic confidence during this period that all phenomena would ultimately be explained in terms of machine mechanisms caused the term 'mechanism' to gradually lose its distinctive mechanistic connotations, becoming a 'dead metaphor' that came to informally signify a commitment to causal explanation-no more and no less. Philosophically, I have argued that judging by the way biologists today use this notion, causal mechanisms are better understood as heuristic explanatory devices than as real things in nature, and that the reason why most mechanismic philosophers think otherwise is because they inadvertently transpose the ontic status of machine mechanisms onto their analyses of causal mechanisms. I have shown that by conceiving causal mechanisms epistemically it is possible to come to terms with the multitude of different biological contexts in which they are featured. My examination has also revealed that biologists today who habitually resort to the concept of 'mechanism' in their explanations are not necessarily mechanists, as the contemporary appeal to mechanism-talk neither entails nor derives from the ontological and epistemological commitments of mechanicism. Mechanismic explanations (i.e., explanations given in terms of causal mechanisms) need not be mechanistic; in fact they often deal with population-level phenomena, such as the causal mechanism of natural selection.

As my historico-philosophical analysis of the concept of 'mechanism' has been restricted to biology, it would be interesting to see whether similar analyses in other sciences support or conflict with the conclusions arrived at here for biology, such as the thesis that causal mechanisms are explanations rather than real things. Ramsey (2008) has recently examined the role of mechanisms in organic chemistry, and one of his main findings is that 'Organic chemists take mechanisms to be explanations' (Ramsey, 2008, p. 976) in the form of 'inferences based on observational data' (ibid., p. 972) ${ }^{16}$ This suggests that the epistemic account of causal mechanisms that I have defended is probably applicable to other areas of science outside of biology. Expanding the range of perspectives on scientific practice should help provide further insight into the role played by the concept of 'mechanism' across the sciences.

\section{Acknowledgements}

I thank Lenny Moss, John Dupré, Paul Griffiths, Staffan MüllerWille, Maureen O'Malley, Sabina Leonelli, and three anonymous

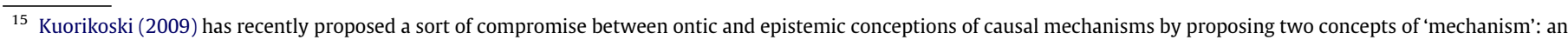

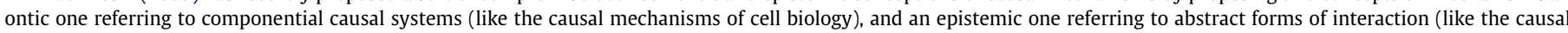

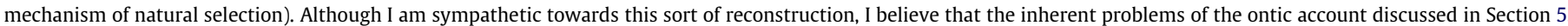
together with the broad applicability of an epistemic view, justifies defending a general epistemic conception of causal mechanisms.

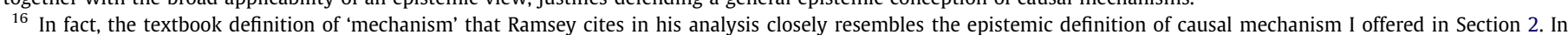

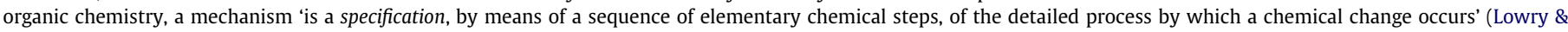
Richardson, 1981, p. 174, my emphasis).
} 
reviewers for helpful comments on earlier versions of this paper. I also thank audiences at the ESRC Centre for Genomics in Society at Exeter (UK), the biennial meeting of the International Society for the History, Philosophy, and Social Studies of Biology held in Brisbane (Australia), and the Konrad Lorenz Institute for Evolution and Cognition Research in Altenberg (Austria), for feedback on presentations on this topic. Finally, I gratefully acknowledge financial support from the University of Exeter, where much of the work for this paper was carried out.

\section{References}

Alberts, B. (1998). The cell as a collection of protein machines: Preparing the next generation of molecular biologists. Cell, 92, 291-294.

Allen, G. (2005). Mechanism, vitalism, and organicism in late nineteenth and twentieth-century biology: The importance of historical context. Studies in History and Philosophy of Biological and Biomedical Sciences, 36, 261-283.

Barros, D. B. (2008). Natural selection as a mechanism. Philosophy of Science, 75 $306-322$.

Bechtel, W. (2006). Discovering cell mechanisms: The creation of modern cell biology. Cambridge: Cambridge University Press.

Bechtel, W. (2007). Biological mechanisms: Organized to maintain autonomy. In F. C. Boogerd, F. J. Bruggerman, J. S. Hofmeyr, \& H. V. Westerhoff, et al. (Eds.) Systems biology: Philosophical foundations (pp. 269-302). New York: Elsevier.

Bechtel, W. (2008). Mental mechanisms: Philosophical perspectives on cognitive neuroscience. London: Routledge.

Bechtel, W. (2009). Generalization and discovery by assuming conserved mechanisms: Cross-species research on circadian oscillators. Philosophy of Science, 76, 762-773.

Bechtel, W., \& Abrahamsen, A. (2008). From reduction back to higher levels. In Proceedings of the $30_{\text {th }}$ Annual Meeting of the Cognitive Science Society.

Bechtel, W., \& Richardson, R. C. (1993). Discovering complexity: Decomposition and localization as strategies in scientific research. Princeton: Princeton University Press.

Bertalanffy, L. v. (1952). Problems of life: An evaluation of modern biological and scientific thought. New York: Harper \& Brothers.

Bie, B., \& Pan, Z. (2007). Trafficking of central opioid receptors and descending pain inhibition. Molecular Pain, 3, 1-7.

Brandon, R. N. (1985). Grene on mechanism and reductionism: More than just a side issue. In P. Asquith \& P. Kitcher (Eds.). PSA 1984 (Vol. 2, pp. 345-353). EastLansing, MI: Philosophy of Science Association.

Brandon, R. N. (1996). Concepts and methods in evolutionary biology. Cambridge: Cambridge University Press.

Broad, C. D. (1925). The mind and its place in nature. London: Kegan Paul.

Bunge, M. (1997). Mechanism and explanation. Philosophy of the Social Sciences, 27 410-465.

Craver, C. F. (2005). Beyond reduction: Mechanisms, multifield integration, and the unity of neuroscience. Studies in History and Philosophy of Biological and Biomedical Sciences, 36, 373-397.

Craver, C. F. (2006). When mechanistic models explain. Synthese, 153, 355-376.

Craver, C. F. (2007). Explaining the brain: Mechanisms and the mosaic unity of neuroscience. New York: Oxford University Press.

Craver, C. F., \& Darden, L. (2005). Introduction. Studies in History and Philosophy of Biological and Biomedical Sciences, 36, 233-244.

Darden, L. (2005). Relations among fields: Mendelian, cytological and molecular mechanisms. Studies in History and Philosophy of Biological and Biomedical Sciences, 36, 357-371.

Darden, L. (2006). Reasoning in biological discoveries: Essays on mechanisms, interfield relations, and anomaly resolution. Cambridge: Cambridge University Press.

Darden, L. (2007). Mechanisms and models. In D. L. Hull \& M. Ruse (Eds.), The Cambridge companion to philosophy of biology (pp. 139-159). Cambridge: Cambridge University Press.

Darden, L. (2008). Thinking again about biological mechanisms. Philosophy of Science, 75, 958-969.

Dawkins, R. (1986). The blind watchmaker. New York: W. W. Norton.

Dennett, D. C. (1995). Darwin's dangerous idea. New York: Simon \& Schuster.

Dobzhansky, T. (1937). Genetics and the origin of species. New York: Columbia University Press

Dupré, J. (2007). The constituents of life. Assen: Van Gorcum.

Edin, B. B. (2008). Assigning biological functions: Making sense of causal chains. Synthese, 161, 203-218.

Falleti, T. G., \& Lynch, J. F. (2009). Context and causal mechanisms in politica analysis. Comparative Political Studies, 42, 1143-1166.

Fisher, R. A. (1930). The genetical theory of natural selection. Oxford: Oxford University Press

Gerring, J. (2007). The mechanismic world view: Thinking inside the box. British Journal of Political Science, 38, 161-179.

Glennan, S. (1996). Mechanisms and the nature of causation. Erkenntnis, 44, 49-71.
Glennan, S. (2002). Rethinking mechanistic explanation. Philosophy of Science, 69(1), S342-S353.

Glennan, S. (2005a). Modeling mechanisms. Studies in History and Philosophy of Biological and Biomedical Sciences, 36, 443-464.

Glennan, S. (2005b). Is there a mechanism of natural selection? Paper presented at the International Society for the History, Philosophy, and Social Studies of Biology meeting in Guelph, Canada, July 2005. (Abstract: <http://www.ishpssb.org/ocs/ viewabstract.php?id=215>).

Grene, M. (1971). Reducibility: Another side issue? In M. Grene (Ed.), Interpretations of life and mind (pp. 14-37). New York: Humanities Press.

Gould, S. J., \& Lewontin, R. (1979). The spandrels of San Marco and the Panglossian paradigm: A critique of the adaptationist programme. Proceedings of the Royal Society of London, 205, 581-598.

Haldane, J. S. (1929). The sciences and philosophy. London: Hazell, Watson \& Viney, Ltd..

Haldane, J. S. (1931). The philosophical basis of biology. London: Hodder \& Stoughton Ltd.

Haldane, J. B. S. (1932). The causes of evolution. London: Longmans, Green.

Hempel, C. G. (1966). Philosophy of natural science. London: Prentice-Hall International, Inc.

Johnstone, J. (1914). The philosophy of biology. Cambridge: Cambridge University Press.

Kauffman, S. A. (1970). Articulation of parts explanation in biology and the rational search for them. PSA: Proceedings of the Biennial Meeting of the Philosophy of Science Association, 1970, 257-272.

Kuorikoski, J. (2009). Two concepts of mechanism: Componential causal system and abstract form of interaction. International Studies in the Philosophy of Science, 23, $143-160$.

Lewens, T. (2004). Organisms and artifacts. Cambridge, MA.: MIT Press.

Lewontin, R. C. (2000). The triple helix: Gene, organism, and environment. Cambridge, MA.: Harvard University Press.

Loeb, J. (1912). The mechanistic conception of life. Chicago: Chicago University Press.

Lowry, T., \& Richardson, K. (1981). Mechanism and theory in organic chemistry. New York: Harper \& Row.

Machamer, P. (2004). Activities and causation: The metaphysics and epistemology of mechanisms. International Studies in the Philosophy of Science, 18, 27-39.

Machamer, P., Darden, L., \& Craver, C. F. (2000). Thinking about mechanisms. Philosophy of Science, 67, 1-25.

Maturana, H. R., \& Varela, F. J. (1980). Autopoiesis and cognition: The realization of the living. Boston: Reidel.

McKay, P., \& Williamson, J. (2010). Function and organization: Comparing the mechanisms of protein synthesis and natural selection. Studies in History and Philosophy of Biological and Biomedical Sciences, 41, 279-291.

McLaughlin, P. (2001). What functions explain: Functional explanation and selfreproducing systems. Cambridge: Cambridge University Press.

Monod, J. (1977). Chance and necessity: An essay on the natural philosophy of modern biology. Glasgow: Williams Collins Sons \& Co Ltd. (First published 1970).

Mossio, M., Saborido, C., \& Moreno, A. (2009). An organizational account of biological functions. British Journal for the Philosophy of Science, 60, 813-841.

Nagel, E. (1979). The structure of science. Indianapolis: Hackett Publishing Company.

Needham, J. (1925). Mechanistic biology and the religious consequences. In J. Needham (Ed.), Science, religion and reality (pp. 219-258). New York: The Macmillan Company.

Norkus, Z. (2005). Mechanisms as miracle makers? The rise and inconsistencies of the 'mechanismic approach' in social science and history. History and Theory, 44, 348-372.

Railton, P. (1978). A deductive-nomological model of probabilistic explanation. Philosophy of Science, 45, 206-226.

Ramsey, J. (2008). Mechanisms and their explanatory challenges in organic chemistry. Philosophy of Science, 75, 970-982.

Rosen, R. (1991). Life itself: A comprehensive inquiry into the nature, origin, and fabrication of life. New York: Columbia University Press.

Ruse, M. (2005). Darwinism and mechanism: Metaphor in science. Studies in History and Philosophy of Biological and Biomedical Sciences, 36, 285-302.

Salmon, W. C. (1984). Scientific explanation and the causal structure of the world. Princeton, NJ: Princeton University Press.

Skipper, R., \& Millstein, R. (2005). Thinking about evolutionary mechanisms: Natural selection. Studies in History and Philosophy of Biological and Biomedical Sciences, 36, 327-347.

Thagard, P. (1998). Explaining disease: Causes, correlations, and mechanisms. Minds and Machines, 8, 61-78.

Torres, P. J. (2009). A modified conception of mechanisms. Erkenntnis, 71, 233-251.

Varela, F. J., \& Maturana, H. R. (1972). Mechanism and biological explanation. Philosophy of Science, 39, 378-382.

Wimsatt, W. C. (1972). Complexity and organization. In PSA: 1972, Proceedings of the Philosophy of Science Association, pp. 67-86.

Wimsatt, W. C. (1974). Reductive explanation: A functional account. In PSA: 1974, Proceedings of the Philosophy of Science Association, pp. 671-710.

Woodger, J. H. (1929). Biological principles. London: Routledge \& Kegan Paul.

Woodward, J. (2003). Making things happen: A theory of causal explanation. Oxford: Oxford University Press. 